\title{
A method of analysis of complex hydraulic networks
}

\author{
Leonid Duginov ${ }^{1}$, Michael Rozovskiy ${ }^{2}$, and Leonid Korelstein ${ }^{3 *}$ \\ ${ }^{1}$ OOO Fundamentproekt, Moscow, Russia \\ ${ }^{2}$ OOO Fundamentproekt, Moscow, Russia \\ ${ }^{3}$ Piping System Research \& Engineering Co (PSRE Co), Moscow, Russia
}

\begin{abstract}
A simple and reliable iterative solution method of classical hydraulic network flow rate distribution problem is described. The method is based on chord linearization of inverse branch loss function which keeps basic branch properties. It has good speed of convergency which is practically independent of initial values.
\end{abstract}

\section{Introduction}

The article describes hydraulic network flow rate distribution calculation method, successfully used from 1972 year (([1], [2], [3]).

Various methods of solving classical hydraulic network flow rate distribution problem have been investigating already during almost a century, starting from Lobachev - Hardy Cross method $[4,5]$. The most popular in the last time are different variants of iterative methods based on Newton-Raphson algorithm, which use derivative linearization of hydraulic network equations in different forms: methods of Linear Theory (LT) [8], Loop Flow (LP) $[6,7,9,10]$, Nodal Adjustment method (NA) [6, 7, 11, 12], and Global Gradient Algorithm (GGA) [13, 14]. The review of these methods can be found in [Ошибка! Источник ссылки не найден., 16], where their uniform nature is shown. Another recent variant of such methods is Reformulated Co-Tree Method (RCTM) [17], combining GGA and LP and more effective in some cases (but demanding topological analysis of the network). Further efforts to make LP more effective can be found also in [18].

In the same time some "non-Newtonian" approaches were considered based on chord or secant network equations linearization. Such methods were originally proposed in [19, 20] and then in [7], and also mentioned in [21]. Systematic research of such methods was done in article [22]. Note that many of such methods found out to be very efficient.

The method described in this article also belongs to chord linearization type of methods and was listed (among others) in [22], but was described there as not universal enough one because of its linearization problem for zero (or near zero) flow rate branches. And

\footnotetext{
${ }^{*}$ Leonid Korelstein: Korelstein@truboprovod.ru
} 
really this problem theoretically exists, but in practice it disappears if laminar flow is taken into account in this case.

\section{Method description}

Well known hydraulic network equations of classical flow rate distribution problem can be written as

$$
\begin{aligned}
& A^{T} P=F(X) \\
& A X=Q
\end{aligned}
$$

Where $A$ - incidence matrix of the network, $X$ - vector of mass flow rates, $Q$ - node mass inflow vector, $P$ - vector of node potentials (pressures), $F(X)$ - vector function, each element of which is function of losses on edges.

It is supposed that node pressures are set in part of nodes (at least one), and inflows are defined in remaining nodes.

The proposed method (called Estimated Flow Rate - EFR) is to replace system (1), (2) by similar linear system on each iteration, in which nonlinear vector function $F(X)$ is replaced by linear vector function $F_{L}(X)=A_{L} X+F_{0}, F_{0}=F(0)$, correspondent to chord of function $F(X)$ (or inverse function $\varphi$ to it), connecting point of current iteration and zero flow rate point.

Thus, on i-th iteration the linear system to be solved is

$$
\begin{aligned}
& A^{T} P^{(i)}=A_{L}^{(i)} X^{(i)}+F_{0} \\
& A X^{(i)}=Q
\end{aligned}
$$

Where elements of diagonal matrix $A_{L}^{(i)}$ on each iteration are calculated via equation

$$
a_{L j j}^{(i)}=\left(h_{j}^{(i-1)}-F_{0 j}\right) / X_{L j}^{(i-1)},
$$

with estimated flow rate $X_{L j}^{(i-1)}=\varphi\left(h_{j}^{(i-1)}\right), h^{(i-1)}=A^{T} P^{(i-1)}$

In the seldom case when flow rate on the edge equals zero, and formula (5) is undefined, $a_{L j j}^{(i)}=\frac{d F_{j}}{d X_{j}}(0)$ should be used instead of (5), with derivative calculated analytically or numerically (in order this derivative be non-zero, laminar type of the flow in this case should be considered [23]!).

For typical quadratic losses (according Darcy-Weisbach equation) on passive j-th edge $F_{j}\left(X_{j}\right)=\lambda_{j}\left|X_{j}\right| X_{j}$ equation (5) gives $a_{L j j}^{(i)}=\sqrt{\lambda_{j}\left|h_{j}^{(i-1)}\right|}$, for general power losses $F_{j}\left(X_{j}\right)=$ $\lambda_{j}\left|X_{j}\right|^{n-1} X_{j}$ (5) gives $a_{L j j}^{(i)}=\lambda_{j}^{1 / n}\left|h_{j}^{(i-1)}\right|^{1-1 / n}$. However, in principle loss function $F(X)$ can be arbitrary function and can be even defined by the table. As this function usually is monotonic and smooth enough [23], effective calculation of inverse function on every iteration is not a problem - there are now known many highly effective derivative-free root finding algorithms for solving such problems (direct and inverse quadratic interpolation, modified Pegasus method [27, 28], Brent method [26] etc. - see survey of such methods in $[24,25])$, which allow to calculate inverse function with required practical accuracy via 3-4 iterations.

\section{Method advantages}


EFR method (as chord linearization method) has linear convergency, but its convergency speed is quite good (especially for flow rates) - most often in practice no more than 5-7 iterations are needed.

The biggest advantage of the method is its high stability and practical independency of initial point. As many years of usage experience showed, EFR allows to set practically any initial flow rate and node pressure values, and number of iterations is almost independent of these values (initial flow directions on edges can be set also arbitrary - they will be automatically corrected during iterations). Moreover, already after the first iteration node pressure values are usually close enough to the solution, and this minimizes risk of occasional «blowout» of node pressures during iterations into zone where the model is not adequate (fluid is boiling or condensing, or choked flow occurs). This can be easily explained - on each iteration original network is replaced by linear one with similar edge properties - passive edges remain passive, and active edges have the same head at zero flow rate - so for solutions on each iteration the same theorems (proved in [28]) for network solutions in restricted node pressure space is applied, as for original network problem. This advantage of EFR allows to apply it also in combination with other methods (for example GGA) to get better initial approximation for them.

The method stability allows also to use it (in combination with decomposition method) for thermal and hydraulic calculations taking into account dependence of fluid temperature on pressures and flow rates.

Finally, the simplicity of the method allows to use it for training of hydraulic network analysis foundations for non-specialists.

\section{Example}

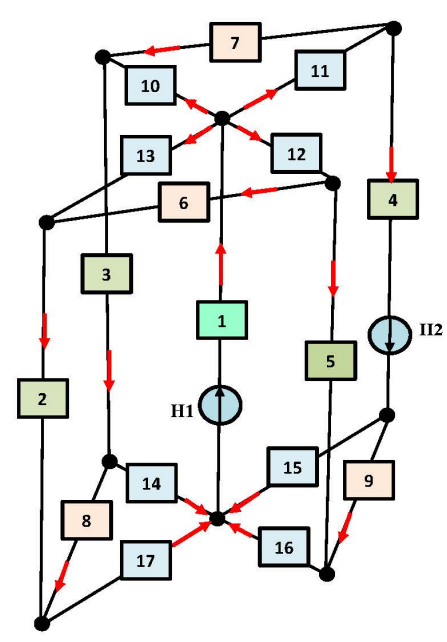

Example of multi-looped piping network (transferring air) is shown on Ошибка! Источник ссылки не найден., with edge 1 being part of four loops. Each edge contains at least entrance, pipe and exit elements taking into account correspondent local or friction losses. Air density dependence on pressure is also considered. Edges 1 and 4 contain active elements - fans $\mathrm{H} 1$ and $\mathrm{H} 2$. Other edges are passive.

Relative error of flow rate values on different iterations are shown in table 1.

\begin{tabular}{|c|c|c|c|c|}
\hline $\begin{array}{c}\text { Iteration } \\
\mathrm{N}\end{array}$ & 6 & 7 & 8 & 9 \\
\hline $\begin{array}{c}\text { Relative } \\
\text { error }\end{array}$ & $4 \cdot 10^{-2}$ & $2 \cdot 10^{-3}$ & $4 \cdot 10^{-4}$ & $5 \cdot 10^{-5}$ \\
\hline
\end{tabular}

Table 1. Relative error vs iteration number

Fig. 1. Example of piping network

\section{References}

1. V.Yu. Avruh, L.A. Duginov, et al. Russian Electrical Engineering, 12 (1975) [in Russian] 
2. V.Yu. Avruh, L.A. Duginov. Thermal and hydraulic procesess in turbo- and hydrogenerators, 50 (Moscow, Energoatomizdat, 1991) [in Russian]

3. I.F. Filippov. Heat transfer in electrical machines, 204 (1986) [in Russian]

4. V.G. Lobachev. Sanitary technics, 2, 8 (1934)

5. H. Cross. Engineering Experimental Station, 286, 3 (1936)

6. M.G. Suharev, E.R. Stavrovsky. Gas transport systems analysis using computers (Moscow, Nedra, 1971) [in Russian]

7. A.P. Merenkov, V.Y. Hasilev. Theory of Hydraulic Circuits (1985) [in Russian]

8. D.J. Wood, C.O.A. Charles. J. Hydraul. Div. ASCE, 98, 7, 1157 (1972)

9. R. Epp, A.G. Fowler. J. Hydraul. Div. ASCE, 96, 1, 43 (1970)

10. H.K. Kesavan, M. Chandrashekar. J. Hydraul. Div. ASCE, 98, 2, 345 (1972)

11. D.W. Martin, G. Peters, J Institute Water Engineers, 17, 115 (1963)

12. U. Shamir, C.D.D. Howard, J. Hydraul. Div. ASCE, 94, 219 (1968)

13. E. Todini. Bollettino degli Ingegneri della Toscana, 11 (1979)

14. E. Todini, S. Pilati. In B. Coulbeck and C.H. Orr (eds). Computer Applications in Water Supply, 1 (System analysis and simulation), 1 (London: John Wiley \& Sons, 1988)

15. M.G. Suharev. Piping Systems of Energetics: Control of development and operation, 15 (Novosibirsk, Nauka, 2004) [in Russian]

16. E. Todini. In R. Powell and K.S.Hindi (eds) Computing and Control for the Water Industry, 63 (Baldock, UK: Research Studies Press Ltd, 1999)

17. S. Elhay, A.R. Simpson, J. Deuerlein, B. Alexander, W.H.A. Schilders. J. Water Resour. Plann. Manage. (2014)

18. F. Alvarruiz, F. Martnez-Alzamora, A.M. Vidal. J. Water Resour. Plann. Manage. 141(10), 04015019 (2015)

19. V.Ya. Khasilev. Izv. Akad. Nauk SSSR, Energetika Transport, 2, 231 (1964) [in Russian]

20. V.Ya. Khasilev. Izv. Akad. Nauk SSSR, Energetika Transport, 1, 69 (1964) [in Russian]

21. N.I. Baranchikova S.P. Epifanov V.I. Zorkaltsev. Water and Ecology. 2, 31 (2014) [in Russian]

22. N.N. Novitskii. Thermal Engineering, 60, 14, 1051 (2013)

23. I.E. Idelchik. Handbook of Hydraulic Resistance, 4th Edition Revised and Augmented. (New York, Begell House, 2008)

24. S. Intep. Applied Mathematical Sciences, 12, 3, 137 (2018)

25. G. E. Alefeld, F. A. Potra, Y. Shi. ACM Transactions on Mathematical Software, 21, 3, 327 (1995)

26. R.P. Brent. Algorithms for Minimization without Derivatives, Chapter 4. Prentice- Hall, +Englewood Cliffs, NJ. ISBN 0-13-022335-2 (1973)

27. R. F. King. Computing, 17, 49 (1976)

28. R.F. King. BIT 13, 423 (1973)

29. L. Korelstein. E3S Web of Conferences. 102, 01004 (2019) 